\title{
The role of test stimuli in matching to compound samples by pigeons
}

\author{
WILLIAM S. MAKI, JR. \\ North Dakota State University, Fargo, North Dakcta 58102 \\ DONALD A. RILEY \\ University of California, Berkeley, California 94720 \\ and \\ CHARLES R. LEITH \\ Northern Michigan University, Marquette, Michigan 49855
}

\begin{abstract}
Two pigeons matched to sample in a three-key operant conditioning chamber. In Experiment I, two different kinds of samples were presented on the center key. Element samples were members of one of two sample sets - colors (a red or blue disk) or lines (a vertical or horizontal orientation of a set of white lines). These samples were followed by their respective sample sets on the side keys as comparison stimuli. Compound samples consisted of a set of lines superimposed on a colored disk. Following these samples, either sample set could appear as comparison stimuli. Matching to compound samples was less accurate than matching to element samples. One interpretation is that sharing of attention among elements of a compound sample weakened stimulus control by each element. A different interpretation is that an element sample controlled matching better because it was physically identical to a comparison stimulus whereas a compound sample was not. Experiments II-IV evaluated this "generalization decrement" alternative by testing element- vs. compound sample control with both element and compound comparison stimuli. Irrelevant elements were added to form compound comparison stimuli, some of which were physically identical to a preceding compound sample, but never identical to an element sample. In all experiments, the addition of irrelevant elements of comparison stimuli reduced sample control. However, the generalization decrement hypothesis failed to predict how differences in performance maintained by element and compound samples were affected by different tests of sample control. Matching accuracy appeared to be independently determined by the number of elements in a sample and whether irrelevant elements were present during tests of sample control.
\end{abstract}

A common observation is that stimulus control may be unequally distributed among elements of a complex stimulus. Such effects have been interpreted as instances of selective attention to the controlling stimuli (Sutherland \& Mackintosh, 1971). Demonstrations of selective stimulus control have taken two forms. If responses are reinforced in the presence of a compound stimulus, some elements come to control responding and others do not (e.g., Born \& Peterson, 1969; Reynolds, 1961). If responses are reinforced in the presence of Element $A$, and then reinforced in the presence of Compound $A B$, Element $\mathrm{B}$ assumes little if any control over responding (e.g., Johnson \& Cumming, 1968; Kamin, 1969).

A general rule has been composed which describes the findings of a large number of experiments on selective attention. The rule has been phrased in different ways (Born \& Peterson, 1969; Mackintosh, 1965), but it essentially states that "...the degree of control exerted by one element of a compound stimulus is inversely related to the stimulus control exerted by other

This research was supported by USPHS Grants MH22153 and FR-7006 Biomedical Support Grant to D. A. Riley. W. S. Maki was supported by USPHS Predoctoral Traineeship MH10878. Experiments II and III were reported at the meeting of the Psychonomic Society, St. Louis, 1973. We thank David Carter for comments on an earlier version of this paper.

Send reprint requests to W. S. Maki, Jr., Department of Psychology, North Dakota State University, Fargo, North Dakota 58102 . elements of the compound" (Maki \& Leith, 1973, p. 348). There are two major implications. First, if Element $\mathrm{A}$ of Compound $\mathrm{AB}$ strongly controls responding, Element $B$ will only control responding weakly, if at all; likewise, if control by Element $B$ is strong, control by Element A will be weak. This is supported by a substantial body of literature (see Sutherland \& Mackintosh, 1971). Second, if control by both elements is more or less equal, then control by each element may be reduced when they appear in compound. Experimental support for this implication is less well documented (Blough, 1969; Leith \& Maki, 1975; Maki \& Leith, 1973; Maki \& Leuin, 1972).

In the Maki and Leith experiment, pigeons performed a matching-to-sample (MTS) task. Each trial started when the center key of a three-key display was illuminated by a white light. A single peck at the key resulted in the display of a sample stimulus on this same key. After a variable period of time, the center key was darkened and the two side keys were illuminated by comparison stimuli, one of which "matched" the sample. A response to the matching stimulus resulted in reinforcement. Comparison stimuli consisted of red and blue disks, or vertical and horizontal orientations of three white lines on a black ground. Sample stimuli were of two types. One-half, element samples, were one of the four simple stimuli. When a color appeared as a sample, colors 
appeared as comparison stimuli; when a set of lines appeared as a sample, lines appeared as comparison stimuli. The other half of the samples were compound stimuli (white lines superimposed on a colored ground). Compound samples were followed by either color or line comparisons. In general, compound samples controlled matching choices less well than did element samples. This finding was dubbed "shared attention;" when both elements of a compound sample share control of behavior, control by each is attenuated.

In the present paper four experiments are described. The first was a systematic replication of Maki and Leith's experiment employing a somewhat simpler procedure. In Experiments II-IV, elements and compound samples were followed by element or compound comparison stimuli. In Experiment II, compound comparison stimuli shared an identical, "irrelevant" element so that one compound comparison exactly matched a compound sample, but was never identical to an element sample. In Experiment III, compound comparisons contained a common irrelevant element such that comparisons were never identical to either element or compound samples. In Experiment IV, compound comparisons were constructed so that elements were redundant and relevant during compound-sample trials, but some elements of compound comparisons were irrelevant during element-sample trials.

The latter three experiments are relevant to two issues. First, it has been claimed (but not demonstrated) that testing compound-sample control with elements eliminates competing response tendencies associated with values on other dimensions which would otherwise be present during testing (Farthing \& Opuda, Reference Note 1; Leith \& Maki, 1975; Maki \& Leith, 1973). This characteristic of MTS may not be true of other procedures (Blough, 1969). Introduction of such additional stimuli during the comparison stage of MTS should reduce matching accuracy. Second, the Maki and Leith findings are subject to interpretations phrased in terms other than "shared attention." These alternatives are based on the method used to assess control by elementvs. compound-sample stimuli. Element samples were always followed by a display containing a stimulus which was identical to the sample. Compound samples were followed by the same comparison stimuli, neither of which was an exact match. For example, if the sample was a red disk, the comparison stimuli were red and blue disks. If, however, the sample contained white vertical lines on a red ground, the comparison stimuli were either red and blue disks, or sets of white lines on black grounds.

One alternative to a shared-attention interpretation is the "generalization decrement hypothesis." This hypothesis argues that control by compound samples is reduced due to the lack of an exactly matching comparison stimulus. Although weakened by evidence obtained in studies of "symbolic matching" (Carter \& Eckerman, 1975; Cumming \& Berryman, 1965, p. 300), the general- ization decrement hypothesis still rivals the sharedattention hypothesis and needs direct experimental examination.

Yet another alternative interpretation views acquisition of MTS as the learning of a set of "if ...then..." rules, and the rate of acquisition being determined by the number of rules to be learned (Carter \& Eckerman, 1975). For example, the rule governing matching to a red disk might be "if red center, peck red side." For every elemental sample, then, there exists a single rule. For every compound sample, however, there are two rules; e.g., "if red-vertical, peck red" and "if red-vertical, peck vertical" are the two rules associated with a redvertical compound sample. A "rule" hypothesis, therefore, also predicts matching to compound samples to be worse than matching to element samples, if one assumes that MTS performance, like acquisition, also depends on the number of rules present in a particular version of MTS.

\section{GENERAL METHOD}

\section{Subjects}

Two white Carneaux pigeons (Nos. 67 and 69) with extensive MTS experience served as subjects. For each bird, this prior experience consisted of 68,800 MTS trials distributed over several months of daily training. On one-half of these trials, lines appeared as comparison stimuli, and on one-half, colors appeared. One-half of the trials contained element samples and one-half contained compound samples. Each bird obtained its entire daily ration of mixed grain in the experimental chamber; this procedure maintained the birds at $85 \%-90 \%$ of their free feeding body weights.

\section{Apparatus}

The apparatus has been described in detail by Maki and Leith (1973). Briefly, the pigeons worked in a three-key operant chamber housed in a sound-attenuated room. Each key was backed by an inline projector equipped to project red, white, and blue disks and vertical and horizontal orientations of three white lines on a black ground. Stimuli were compounded by simultaneously lighting two cells of the projector. Reinforcement scheduling, stimulus presentation, and data collection were handled by a Digital Equipment Corporation PDP-8/1. computer equipped with an online teletypewriter and located in an adjacent room.

\section{EXPERIMENT I}

The first experiment was a systematic replication of the Maki and Leith (1973) experiment. The present experiment serves to introduce "shared attention," procedures, results, and hypothesis, which Experiments II-IV critically examine. The prior experiments (Leith \& Maki, 1975; Maki \& Leith, 1973; Maki \& Leuin, 1972) and those reported here involved measuring stimulus control as a function of sample stimulus duration. Maki and Leith, for example, varied sample stimulus duration from trial to trial. The present experiment attempted to repeat their observations with a simpler procedure, i.e., when sample stimulus duration was held constant within each session, but varied between sessions. 
Procedure

The specific procedures were identical to those described by Maki and Leith with few exceptions. During each of the 320 trials composing a session, a single peck on the center key resulted in the replacement of a white disk with the sample stimulus. After a specified period of time fand independently of keypecking), the center key was darkened and the side keys were illuminated by the comparison stimuli. A peck to the side key containing the "matching" stimulus terminated the comparison stimuli and produced reinforcement $(1.8 \mathrm{sec}$ access to mixed grain) on a random $50 \%$ of the trials. A peck to the other side key delayed offset of the comparison stimuli by $2 \mathrm{sec}$, during which time additional pecks were neither effective nor recorded. After a 5-sec timeout, the next trial was initiated.

If the elemental sample was a color, then the two colors were presented as comparison stimuli. If the sample was a set of lines, the two differently oriented sets of lines were later presented. If the sample was a compound stimulus, either set of comparison stimuli was likely to be presented with a probability of 0.50 . Table 1 outlines the different types of trials used in all four experiments. This experiment's trials are summarized in the top portion of the table ("element tests"). The various types of trials were presented in a random order, but frequencies of position of correct choice and matching stimuli were equated within sessions.

Within a given session, sample stimulus duration assumed one of five values $(0.05,0.08,0.10,0.15$, or $2.00 \mathrm{sec})$. Over the 20 sessions in the experiment, each value was present during four sessions. Order of appearance of sample stimulus durations was determined by four randomized blocks of five sessions.

\section{Analysis of data}

Frequencies of correct matching were subjected to a repeated measures analysis of variance. The factors and their levels were sample type (comp vs. element), sample set (matching to colors

Table 1

Configurations of Matching-to-Sample Trials Presented in Experiments I-IV

\begin{tabular}{|c|c|c|c|}
\hline \multicolumn{2}{|c|}{ Color Matching } & \multicolumn{2}{|c|}{ Line Matching } \\
\hline Samples & Comparisons & Samples & Comparisons \\
\hline \multicolumn{4}{|c|}{ Experiments I-IV (Element Tests) } \\
\hline $\begin{array}{l}\mathrm{RV} \text { or } \mathrm{R} \\
\mathrm{RH} \text { or } \mathrm{R} \\
\mathrm{BV} \text { or } \mathrm{B} \\
\mathrm{BH} \text { or } \mathrm{B}\end{array}$ & $\begin{array}{l}\text { R vs. } B \\
R \text { vs. } B \\
R \text { vs. } B \\
R \text { vs. } B\end{array}$ & $\begin{array}{l}\text { RV or } \mathrm{V} \\
\text { RH or } \mathrm{H} \\
\mathrm{BV} \text { or } \mathrm{V} \\
\mathrm{BH} \text { or } \mathrm{H}\end{array}$ & $\begin{array}{l}\text { V vs. } H \\
\text { V vs. } H \\
\text { V vs. } H \\
\text { V vs. } H\end{array}$ \\
\hline \multicolumn{4}{|c|}{ Experiment II (Compound Tests) } \\
\hline $\begin{array}{l}\mathrm{RV} \text { or } \mathrm{R} \\
\mathrm{RH} \text { or } \mathrm{R} \\
\mathrm{BV} \text { or } \mathrm{B} \\
\mathrm{BH} \text { or } \mathrm{B}\end{array}$ & $\begin{array}{l}\text { RV vs. BV } \\
\text { RH vs. BH } \\
\text { RV vs. BV } \\
\text { RH vs. BH }\end{array}$ & $\begin{array}{l}\text { RV or } \mathrm{V} \\
\mathrm{RH} \text { or } \mathrm{H} \\
\mathrm{BV} \text { or } \mathrm{V} \\
\mathrm{BH} \text { or } \mathrm{H}\end{array}$ & $\begin{array}{l}\text { RV vs. } R H \\
\text { RV vs. } R H \\
\text { BV vs. BH } \\
\text { BV vs. BH }\end{array}$ \\
\hline \multicolumn{4}{|c|}{ Experiment III (Compound Tests) } \\
\hline $\begin{array}{l}\mathrm{RV} \text { or } \mathrm{B} \\
\mathrm{RH} \text { or } \mathrm{R} \\
\mathrm{BV} \text { or } \mathrm{B} \\
\mathrm{BH} \text { or } \mathrm{B}\end{array}$ & $\begin{array}{l}\text { RH vs. BH } \\
\text { RV vs. BV } \\
\text { RH vs. BH } \\
\text { RV vs. BV }\end{array}$ & $\begin{array}{l}\text { RV or } \mathrm{V} \\
\text { RH or } \mathrm{H} \\
\mathrm{BV} \text { or } \mathrm{V} \\
\mathrm{BH} \text { or } \mathrm{H}\end{array}$ & $\begin{array}{l}\text { BV vs. } B H \\
\text { BV vs. } B H \\
\text { RV vs. } R H \\
\text { RV vs. } R H\end{array}$ \\
\hline \multicolumn{4}{|c|}{ Experiment IV (Compound Tests) } \\
\hline $\begin{array}{l}\mathrm{RV} \text { or } \mathrm{R} \\
\mathrm{RH} \text { or } \mathrm{R} \\
\mathrm{BV} \text { or } \mathrm{B} \\
\mathrm{BH} \text { or } \mathrm{B}\end{array}$ & $\begin{array}{l}\text { RV vs. BH } \\
\text { RH vs. BV } \\
\text { RH vs. BV } \\
\text { RV vs. BH }\end{array}$ & $\begin{array}{l}\text { RV or } \mathrm{V} \\
\mathrm{RH} \text { or } \mathrm{H} \\
\mathrm{BV} \text { or } \mathrm{V} \\
\mathrm{BH} \text { or } \mathrm{H}\end{array}$ & $\begin{array}{l}\text { RV vs. BH } \\
\text { RH vs. BV } \\
\text { RH vs. BV } \\
\text { RV vs. BH }\end{array}$ \\
\hline
\end{tabular}

Note-Elemental stimuli were red $(R)$ and blue $(B)$ disks and vertical $(V)$ and horizontal $(H)$ orientations of white lines. Compound stimuli are represented as, e.g., $R V$. Comparison stimuli (e.g., $R$ vs. B) also appeared in reverse left-right order (e.g., $B$ vs. $R$ ).
Table 2

Mean Correct Matching as a Function of Bird, Sample Set, Sample Type, and Sample Duration

\begin{tabular}{|c|c|c|c|c|c|c|c|}
\hline \multirow[b]{2}{*}{ Bird } & \multirow[b]{2}{*}{ Set } & \multirow[b]{2}{*}{ Type } & \multicolumn{5}{|c|}{ Duration } \\
\hline & & & 0.05 & 0.08 & 0.10 & 0.15 & 2.00 \\
\hline \multirow[t]{4}{*}{67} & C & $\mathrm{e}$ & 35.5 & 41.2 & 51.2 & 56.8 & 61.8 \\
\hline & & $c$ & 35.2 & 39.2 & 48.0 & 51.2 & 50.0 \\
\hline & L & $\mathrm{e}$ & 32.5 & 42.0 & 46.0 & 50.8 & 62.5 \\
\hline & & $c$ & 32.2 & 35.8 & 37.2 & 47.5 & 57.5 \\
\hline \multirow[t]{4}{*}{69} & C & e & 45.0 & 49.8 & 54.5 & 59.8 & 61.2 \\
\hline & & c & 44.0 & 49.8 & 54.8 & 55.0 & 62.2 \\
\hline & L & $\mathrm{e}$ & 39.8 & 45.0 & 49.0 & 54.8 & 63.8 \\
\hline & & c & 38.2 & 34.2 & 40.0 & 44.0 & 60.2 \\
\hline
\end{tabular}

Note-Birds matched to color $(C)$ or line $(L)$ elements of element (e) or compound (c) samples.

vs. lines), sample duration $(0.05,0.08,0.10,0.15$ vs. $2.00 \mathrm{sec})$, and sessions (1-4). Only the last 256 trials of each session entered into the analysis, so the maximum possible score was 64 . An overall error term was constructed by pooling factor interactions with birds. In this experiment, $\mathrm{MS}_{\text {error }}=19.33(\mathrm{df}=79)$.

\section{Results and discussion}

Performance in terms of mean frequency of correct matching is presented in Table 2 as a function of sample type, sample set, and sample duration for each bird. Averaged over four sessions, each score is based on 256 trials.

Both qualitatively and quantitatively, the effects apparent in Table 2 are similar to those reported by Maki and Leith. Matching accuracy was a monotonically increasing function of sample stimulus duration $[F(4 / 79)=124.25, p<.001]$. Matching to compound samples was less accurate than matching to element samples $[F(1 / 79)=38.49, p<.001)$. Colors were matched better than lines $[F(1 / 79)=44.99, p<.001] .{ }^{1}$

The result to be pursued in this paper is the decreased control of matching by compound relative to element samples. The shared-attention hypothesis places the locus of the effect during sample presentation. Further elaboration of the hypothesis is reserved for general discussion.

\section{EXPERIMENT II}

An alternative explanation of the different performances maintained by element and compound samples emphasizes the physical relations between sample and comparison stimuli. In previous experiments, these relations were not constant for different types of samples. When an element sample occurred during a trial, comparison stimuli were also elements and one of these stimuli was physically identical to the sample. When a compound sample occurred, comparison stimuli were still elements, so no comparison was identical to the sample. It is, therefore, possible that the lack of a physically identical comparison during compound sample trials decreased matching accuracy. 
Table 3

Mean Correct Matching as a Function of Bird, Sample Set, Sample Type, Sample Duration, and Test Type (Experiment In)

\begin{tabular}{|c|c|c|c|c|c|c|c|c|c|c|c|c|}
\hline \multirow[b]{3}{*}{ Bird } & & & \multicolumn{10}{|c|}{ Duration } \\
\hline & \multicolumn{2}{|c|}{ Sample } & \multicolumn{5}{|c|}{ Element Test } & \multicolumn{5}{|c|}{ Compound Test } \\
\hline & Set & Type & .05 & .08 & .10 & .15 & 2.00 & .05 & .08 & .10 & .15 & 2.00 \\
\hline 67 & $\begin{array}{l}\mathrm{C} \\
\mathrm{L}\end{array}$ & $\begin{array}{l}\mathrm{e} \\
\mathrm{c} \\
\mathrm{e} \\
\mathrm{c}\end{array}$ & $\begin{array}{l}32.2 \\
32.2 \\
34.0 \\
33.6\end{array}$ & $\begin{array}{l}40.0 \\
38.6 \\
46.6 \\
38.6\end{array}$ & $\begin{array}{l}43.8 \\
39.4 \\
52.0 \\
45.0\end{array}$ & $\begin{array}{l}54.4 \\
48.0 \\
53.8 \\
50.8\end{array}$ & $\begin{array}{l}62.2 \\
58.2 \\
63.4 \\
63.8\end{array}$ & $\begin{array}{l}35.2 \\
36.0 \\
37.2 \\
34.6\end{array}$ & $\begin{array}{l}38.0 \\
35.0 \\
39.8 \\
35.0\end{array}$ & $\begin{array}{l}38.4 \\
38.2 \\
43.2 \\
36.6\end{array}$ & $\begin{array}{l}41.4 \\
37.4 \\
42.0 \\
39.2\end{array}$ & $\begin{array}{l}60.0 \\
54.4 \\
62.4 \\
60.8\end{array}$ \\
\hline 69 & $\begin{array}{l}\mathrm{C} \\
\mathrm{L}\end{array}$ & $\begin{array}{l}\mathrm{e} \\
\mathrm{c} \\
\mathrm{e} \\
\mathrm{c}\end{array}$ & $\begin{array}{l}36.8 \\
37.0 \\
37.0 \\
33.2\end{array}$ & $\begin{array}{l}48.0 \\
42.6 \\
41.0 \\
34.6\end{array}$ & $\begin{array}{l}49.0 \\
42.0 \\
45.8 \\
40.8\end{array}$ & $\begin{array}{l}56.8 \\
49.6 \\
50.0 \\
42.2\end{array}$ & $\begin{array}{l}62.6 \\
61.8 \\
63.8 \\
61.4\end{array}$ & $\begin{array}{l}33.0 \\
33.2 \\
34.6 \\
32.8\end{array}$ & $\begin{array}{l}37.4 \\
36.4 \\
39.2 \\
33.8\end{array}$ & $\begin{array}{l}41.4 \\
37.2 \\
40.0 \\
35.8\end{array}$ & $\begin{array}{l}45.4 \\
40.6 \\
45.0 \\
42.8\end{array}$ & $\begin{array}{l}61.0 \\
57.8 \\
59.6 \\
56.4\end{array}$ \\
\hline
\end{tabular}

Note-Birds matched to color $(C)$ or line $(L)$ elements of element (e) or compound $(c)$ samples.

Experiment II was designed to test this generalization decrement hypothesis. The strategy was to present compound stimuli after element or compound samples. During element-sample trials, no comparison stimulus was identical to the sample. During compound-sample trials, however, one of the comparison stimuli was identical to the sample. For example, if the compound sample was a set of white vertical lines on a red ground, the comparison stimuli might be vertical vs. horizontal lines, each on a red ground. The corresponding element trial would contain a set of white vertical lines on a black ground followed by the same compound comparison stimuli. As this arrangement reverses the role of generalization decrement in element- and compound sample trials, the performance difference should also be reversed for the generalization-decrement hypothesis to remain viable.

The use of compound comparisons in this experiment also allows evaluation of the rule hypothesis. For each compound sample followed by a set of compound comparison stimuli, only one rule is required for accurate matching (e.g., "if red-vertical, peck red-vertical"). The rule hypothesis, then, predicts that the use of compound comparisons should abolish the difference in performances maintained by element and compound samples. Further, it predicts control of choices among compound comparisons by compound samples (one rule/sample) should be better than control of choices among element comparisons by compound samples (two rules/sample).

\section{Procedure}

Phase 1. Upon completion of Experiment I, the new matching task was introduced. The disctinguishing feature of this task was that all comparison stimuli were compound stimuli. These compounds contained two stimuli, one "relevant" and one "irrelevant." The value of the relevant, to-be-matched element was different on each side key. For compound-sample trials, the irrelevant element appeared in the sample as well as in the subsequently displayed matching alternatives. Consequently, one of the comparison stimuli exactly matched the sample during compound-sample trials. During element-sample trials, however, neither comparison was identical to the sample, as element samples did not contain the irrelevant (comparison) element. These compound-test trials are presented in Table I under "Experiment II."

As in Experiment I, trials were presented in a random sequence, and the following event frequencies were equated: type of sample, to-be-matched element, position of correct matching alternative, value of irrelevant element. All other procedures were the same as those described in Experiment I, except that sample duration was held constant at $5 \mathrm{sec}$. Training was continued until performances stabilized above $90 \%$ correct matching (55 days).

Phase 2. Element tests of sample control were reintroduced. Exactly as in Experiment $I$, these tests consisted of presentation of two elements as comparison stimuli following element or compound samples of 5-sec duration (see Table 1, "element tests"). Each bird performed six sessions of element tests, alternating with six sessions of compound tests. At the end of Phase 2, performance was better than $90 \%$ correct on each combination of sample set, sample type, and test type (compounds vs. elements as comparison stimuli).

Phase 3. As before, sample duration $(0.05,0.08,0.10,0.15$, or $2.00 \mathrm{sec}$ ) was a between-sessions variable; order of appearance was determined by 10 randomized blocks of five sessions each. Each session was randomly assigned one level of test type with the restrictions that each combination of test type and sample duration occurred five times, and that a particular test type did not occur during more than three consecutive sessions. The data from these 50 sessions are reported below.

\section{Results}

Data were analyzed as in Experiment I, except that test type was included as a factor, and sessions contained five levels $\left(\mathrm{MS}_{\text {error }}=17.79, \mathrm{df}=199\right)$.

Each bird's performance (mean frequency of correct matching) is presented in Table 3 as a function of test type, sample type, sample duration, and sample set. Averaged over five sessions, each datum is based on 320 trials.

Once again, element samples were matched better than compound samples $[F(1 / 199)=68.84, p<.001]$, and matching accuracy increased with increasing sample duration $[F(4 / 199)=448.00, p<.001]$. These two variables, sample type and sample duration, significantly interacted $[F(4 / 199)=3.31, p<.05]$; the smallest differences between element- and compound-matching were obtained at the shortest and longest durations. 
Element tests of sample control resulted in better matching than compound tests $[F(1 / 199)=111.79$, $p<.001]$, and this variable interacted with sample duration $[F(4 / 199)=12.59, p<.01]$. Both of these effects are depicted in the top panel of Figure 1; data were averaged over sample set, sample type, sessions, and birds, and transformed to percent correct. As evidenced by the presentation in Figure 1, matching improved less over the four shortest sample durations during compound tests than during element tests.

Data were averaged over sample set, sample duration, sessions, and birds to present the joint influence of sample type and test type on percent correct matching in the top panel of Figure 2. The clear implication of this figure is that the difference between matching to element and compound samples did not depend on testing with elements or compounds. This observation is confirmed by the absence of a significant interaction between sample type and test type $[F(1 / 199)=1.35$, $p<.10] .^{2}$

\section{Discussion}

The results of this experiment stand in contradiction to expectations based on the generalization-decrement and rule hypotheses. When sample control was tested with elements, compound samples controlled matching less well than did element samples. Testing sample control with compounds reduced performance about equally, independently of type of sample. In contrast,

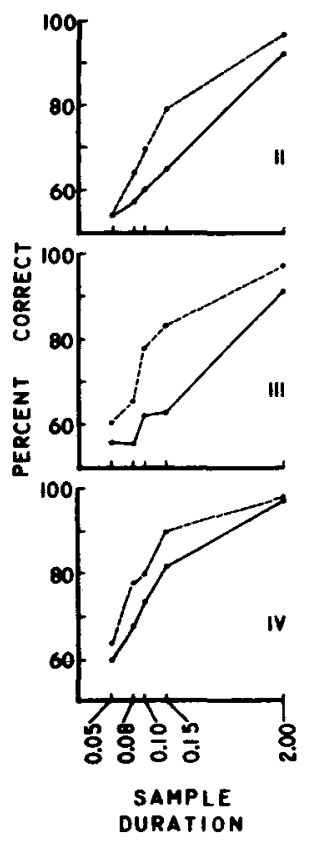

Figure 1. Percent correct matching as a function of sample duration and element (open circles) vs. compound (filled circles) comparison stimuli. Data are averaged over birds, sample type, sample set, and sessions, and are presented separately for Experiments II, III, and IV.

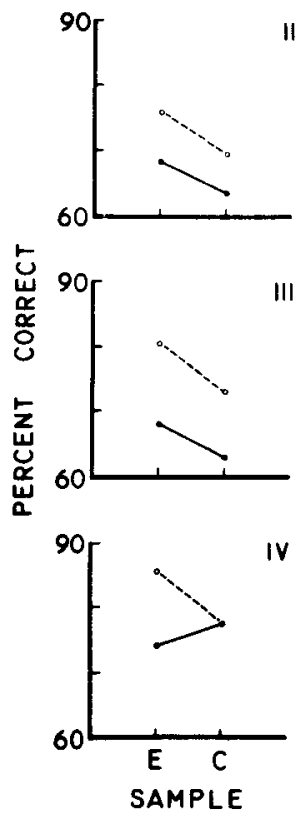

Figure 2. Percent correct matching as a function of element (E) vs. compound (C) samples, and element (open circles) vs. compound (filled circles) comparison stimuli. Data are averaged over birds, sample duration, sample set, and sessions, and are presented separately for Experiments II, III, and IV.

the rule hypothesis predicts an interaction between sample type and test type, i.e., no performance difference attributable to sample type should have occurred when control was tested with compounds. A pure generalization-decrement position also predicts an interaction between sample type and test type, i.e., the performance difference attributable to sample type should have been reversed when control was tested with compounds. However, unqualified rejection of the generalization-decrement hypothesis based on the present results alone would be premature. It may be expected that adding elements to the comparison stimuli introduced additional sources of stimulus control which acted to depress performance. During compound-sample trials, the two compound comparison stimuli contained a common element which was nominally irrelevant but which had appeared in the sample. If, on some proportion of the trials, this common element controlled matching, than any benefits of the presence of an identical comparison stimulus might have been obscured.

The next experiment was designed to test this possibility. If performance on compound sample-compound test trials was depressed because of the irrelevant comparison element and supported by the presence of the comparison stimulus identical to the sample, then removal of the latter source of support should depress performance even further. In Experiment III this prediction was tested by constructing compound comparisons so that the element common to these stimuli was the one which did not appear in the preceding compound 
Table 4

Mean Correct Matching as a Function of Bird, Sample Set, Sample Type, Sample Duration, and Test Type (Experiment III)

\begin{tabular}{|c|c|c|c|c|c|c|c|c|c|c|c|c|}
\hline \multirow[b]{3}{*}{ Bird } & & & \multicolumn{10}{|c|}{ Duration } \\
\hline & \multicolumn{2}{|c|}{ Sample } & \multicolumn{5}{|c|}{ Element Test } & \multicolumn{5}{|c|}{ Compound Test } \\
\hline & Set & Type & .05 & .08 & .10 & .15 & 2.00 & .05 & .08 & .10 & .15 & 2.00 \\
\hline 67 & $\begin{array}{l}\text { C } \\
\text { L }\end{array}$ & $\begin{array}{l}\mathrm{e} \\
\mathrm{c} \\
\mathrm{e} \\
\mathrm{c}\end{array}$ & $\begin{array}{l}39.8 \\
36.8 \\
36.2 \\
35.4\end{array}$ & $\begin{array}{l}44.8 \\
41.6 \\
43.8 \\
35.6\end{array}$ & $\begin{array}{l}54.6 \\
49.6 \\
54.8 \\
43.4\end{array}$ & $\begin{array}{l}56.0 \\
54.4 \\
59.0 \\
50.6\end{array}$ & $\begin{array}{l}61.8 \\
59.8 \\
64.0 \\
63.6\end{array}$ & $\begin{array}{l}35.6 \\
36.4 \\
37.2 \\
32.0\end{array}$ & $\begin{array}{l}36.0 \\
34.6 \\
38.4 \\
34.6\end{array}$ & $\begin{array}{l}41.6 \\
37.6 \\
41.2 \\
39.4\end{array}$ & $\begin{array}{l}42.8 \\
36.4 \\
42.2 \\
36.6\end{array}$ & $\begin{array}{l}59.8 \\
53.6 \\
61.6 \\
61.8\end{array}$ \\
\hline 69 & $\begin{array}{l}\text { C } \\
\text { L }\end{array}$ & $\begin{array}{l}\mathrm{e} \\
\mathrm{c} \\
\mathrm{e} \\
\mathrm{c}\end{array}$ & $\begin{array}{l}45.4 \\
40.4 \\
40.4 \\
34.8\end{array}$ & $\begin{array}{l}49.4 \\
43.2 \\
42.4 \\
34.6\end{array}$ & $\begin{array}{l}56.0 \\
51.0 \\
49.0 \\
39.2\end{array}$ & $\begin{array}{l}56.0 \\
54.8 \\
49.2 \\
44.6\end{array}$ & $\begin{array}{l}62.6 \\
62.8 \\
63.0 \\
60.2\end{array}$ & $\begin{array}{l}36.6 \\
36.0 \\
37.6 \\
35.4\end{array}$ & $\begin{array}{l}40.0 \\
35.8 \\
33.8 \\
31.8\end{array}$ & $\begin{array}{l}41.6 \\
41.0 \\
39.2 \\
35.8\end{array}$ & $\begin{array}{l}46.4 \\
39.4 \\
41.2 \\
35.6\end{array}$ & $\begin{array}{l}52.2 \\
59.6 \\
58.6 \\
53.6\end{array}$ \\
\hline
\end{tabular}

Note-Birds matched to color $(C)$ or line (L) elements of element (e) or compound (c) samples.

sample. For example, following a compound sample of white vertical lines on a red ground, test stimuli might have been a red ground vs. a blue ground, both with horizontal white lines superimposed. It was reasoned that two factors should operate to depress compound sample control of compound-comparison choices generalization decrement and control of matching by the irrelevant element. Once again, an interaction was predicted between sample type and test type, i.e., the effects of test type on performance should be larger during compound-sample trials.

\section{EXPERIMENT III}

\section{Procedure}

Experiment III was conducted exactly like the preceding experiment, except that the irrelevant element present in compound comparison stimuli never matched any element of the sample. The new compound test trials are listed in Table 1. In Phase 1, training continued on compound-test sessions until performance stabilized above $90 \%$ correct ( 50 days). At the end of 10 days of Phase 2 (alternating element- and compound-test sessions), performances exceeded the same criterion. With the exception of the irrelevant element in compound comparisons and randomization procedures, Phase 3 was duplicated in both this and the preceding experiment.

\section{Results and discussion}

Data were analyzed as in Experiment II, and $\mathrm{MS}_{\text {error }}=16.30 \mathrm{df}=199$. Mean frequency of correct matching is presented in Table 4 as a function of bird, test type, sample type, sample set, and sample duration. Each score is based on 320 trials.

Compound samples controlled matching less well than element samples $[F(1 / 199)=92.57, \mathrm{p}<.001]$, and matching improved with longer sample durations $[F(4 / 199)=411.68, p<.001]$. As in Experiment II, the effect of sample type was largest over sample durations of $0.08-0.15 \mathrm{sec}$, resulting in a significant interaction between sample type and sample duration $[F(4 / 199)=2.62, p<.05]$. As in Experiment $I$, colors were matched better than lines $[F(1 / 199)=37.87$, $\mathrm{p}<.001]$.
In important respects, the effects of test type were the same as those obtained in Experiment II. Testing with compounds resulted in worse performance than testing with elements $[F(1 / 199)=315.73, p<.001]$. The interaction between test type and sample duration was significant $[F(4 / 199)=22.60, p<.001]$. The effect of testing sample control with compound stimuli was most pronounced at the four shortest durations; this effect is presented in the middle panel of Figure 1. Finally, the interaction between test type and sample type approached significance $[\mathrm{F}(1 / 199)=3.05$, $.05<\mathrm{p}<.10]$. For both birds, however, the interaction was opposite in direction to that predicted. That is, the effect of test type on performance was slightly smaller during compound-test trials. The effects of these variables on matching are plotted in the middle panel of Figure $2 .^{3}$

The predicted interaction between sample type and test type was not obtained. Consequently, these results, together with those of Experiment II, are inimical to interpretation of the effects of sample type solely in terms of generalization decrement.

\section{EXPERIMENT IV}

The results of the preceding two experiments show that the superiority of performance following element samples is not amenable to interpretation in terms of generalization decrement. It remains to determine why testing sample control with compounds resulted in worse matching than testing control with elements. As noted above, it is likely that adding extra cues to the comparison stimuli resulted in those cues assuming control of responding. Experiment IV was conducted to test implications of the view that accuracy of matching compound-comparison stimuli to compound samples is determined by two variables - shared attention among elements of the compound sample, and presence of competing sources of stimulus control during comparison. Compound comparisons contained two sample sets. Following compound samples, the sets were redundantly 
combined so that both sets were relevant to MTS. Following element samples, only one set was relevant. If added cues sometimes exert control of choices between comparison stimuli, then making these cues relevant should elevate performance to levels observed in the absence of these cues. Consequently, testing control by compound samples with compound comparisons containing redundant and relevant cues should produce matching performances about equal to those obtained with elemental comparison stimuli. However, testing control by element samples with the same compound comparisons should result in a performance loss (relative to testing with elements) similar in magnitude to the losses observed in Experiments II and III.

As in Experiment II, the two rival hypotheses make other predictions. Because an exactly matching compound comparison follows a compound sample, one rule is required for matching. Consequently, the rule hypothesis once again predicts no differences between control of matching by element and compound samples when tested with compound comparisons. It also again predicts that matching compound comparisons to compound samples (one rule/sample) should be (a) better than matching element comparisons to compound samples (two rules/sample), but (b) the same as matching element comparisons to element samples (one rule/sample). The generalization decrement hypothesis also makes the same predictions as in Experiment II. The presence of an exactly matching comparison stimulus in compound sample-compound comparison trials should reverse the performance difference due to compound vs. element samples.

\section{Procedure}

In most respects, this experiment was procedurally the same as Experiments II and III. The major exception was the construction of compound comparison stimuli. Each comparison contained one element from each sample set, and no element was common to the two stimuli. Therefore, during compound sample trials, one comparison stimulus exactly matched the sample, and during element-sample trials, no comparison stimulus was identical to the sample. Representations of both element- and compound-test trials appear in Table 1. Training on compound tests (Phase 1) over 10 sessions resulted in performances uniformly exceeding $90 \%$ correct, as did training over 10 alternating sessions of element and compound tests (Phase 2). Except for construction of compound comparisons, Phase 3 proceeded as in the previous two experiments.

\section{Results}

Data were analyzed as in Experiment II $\left(\mathrm{MS}_{\mathrm{error}}=\right.$ 20.71 , df $=199$ ). Frequencies of correct matching are presented in Table 5 as a function of bird, test type, sample type, sample set, and sample duration. Each score is an average of five sessions ( 320 trials).

Element samples resulted in better matching than did compound samples $[\mathrm{F}(1 / 199)=9.53, \mathrm{p}<.01]$, and matching improved over sample duration $[F(4 / 199)=$ $296.68, p<.001]$. Unlike the results of Experiments II and III, the interaction between sample type and sample duration was not significant. Colors tended to be matched better than lines $[F(1 / 199)=20.40, p<.001]$.

Testing with compounds resulted in poorer matching than testing with elements $[F(1 / 199)=69.19, p<.001]$ and this difference was most marked at intermediate sample durations $[F(4 / 199)=5.40 p<.001]$. The interaction between test type and sample duration is portrayed in the bottom panel of Figure 1. In contrast to the results of Experiments II and III, the interaction between test type and sample type is significant $[F(1 / 199)=67.01, p<.001]$. As shown in the bottom panel of Figure 2, compound samples were matched worst when tested with elements, but were matched best when tested with compounds. On the average, testing control of compound samples with compound comparisons did not reduce performance. ${ }^{4,5}$

\section{Discussion}

Given the failures of Experiments II and III to produce data consistent with predictions of the generalization decrement and rule hypotheses, the present experiment tested predictions derived from a different hypothesis. This alternative view holds that two factors determine matching. First, during presentation of a compound sample, sharing of attention between elements reduces control of matching by each element.

Table 5

Mean Correct Matching as a Function of Bird, Sample Set, Sample Type, Sample Duration, and Test Type (Experiment IV ${ }^{s}$

\begin{tabular}{|c|c|c|c|c|c|c|c|c|c|c|c|c|}
\hline \multirow[b]{3}{*}{ Bird } & & & \multicolumn{10}{|c|}{ Duration } \\
\hline & \multicolumn{2}{|c|}{ Sample } & \multicolumn{5}{|c|}{ Element Test } & \multicolumn{5}{|c|}{ Compound Test } \\
\hline & Set & Type & .05 & .08 & .10 & .15 & 2.00 & .05 & .08 & .10 & .15 & 2.00 \\
\hline 67 & $\begin{array}{l}C \\
L\end{array}$ & $\begin{array}{l}\mathrm{e} \\
\mathrm{c} \\
\mathrm{e} \\
\mathrm{c}\end{array}$ & $\begin{array}{l}38.8 \\
35.2 \\
40.2 \\
32.0\end{array}$ & $\begin{array}{l}52.6 \\
47.4 \\
53.2 \\
45.4\end{array}$ & $\begin{array}{l}53.4 \\
49.0 \\
58.2 \\
46.4\end{array}$ & $\begin{array}{l}61.8 \\
59.0 \\
60.0 \\
54.0\end{array}$ & $\begin{array}{l}63.2 \\
62.0 \\
64.0 \\
63.6\end{array}$ & $\begin{array}{l}35.6 \\
33.8 \\
37.4 \\
38.0\end{array}$ & $\begin{array}{l}39.4 \\
45.4 \\
44.6 \\
40.2\end{array}$ & $\begin{array}{l}42.6 \\
46.2 \\
48.8 \\
47.2\end{array}$ & $\begin{array}{l}47.4 \\
55.6 \\
53.4 \\
55.4\end{array}$ & $\begin{array}{l}61.6 \\
61.6 \\
62.6 \\
64.0\end{array}$ \\
\hline 69 & $\begin{array}{l}\text { C } \\
\text { L }\end{array}$ & $\begin{array}{l}\mathrm{e} \\
\mathrm{c} \\
\mathrm{e} \\
\mathrm{c}\end{array}$ & $\begin{array}{l}51.4 \\
47.2 \\
42.8 \\
37.2\end{array}$ & $\begin{array}{l}57.6 \\
53.6 \\
48.4 \\
40.4\end{array}$ & $\begin{array}{l}58.0 \\
53.4 \\
49.2 \\
41.6\end{array}$ & $\begin{array}{l}62.8 \\
57.2 \\
55.8 \\
49.2\end{array}$ & $\begin{array}{l}63.2 \\
62.2 \\
63.6 \\
59.6\end{array}$ & $\begin{array}{l}40.2 \\
40.2 \\
36.2 \\
42.0\end{array}$ & $\begin{array}{l}41.4 \\
46.0 \\
45.0 \\
44.8\end{array}$ & $\begin{array}{l}49.4 \\
50.8 \\
43.4 \\
46.6\end{array}$ & $\begin{array}{l}52.8 \\
54.0 \\
45.8 \\
54.2\end{array}$ & $\begin{array}{l}61.2 \\
62.2 \\
59.2 \\
63.4 \\
\end{array}$ \\
\hline
\end{tabular}

Note-Birds matched to color (C) or line (L) elements of element (e) or compound (c) samples. 
Second, during presentation of comparison stimuli, additional cues compete for control of choice behavior. The presence of these irrelevant cues (compound tests) reduced matching accuracy relative to their absence (element tests). The reduction for matching to element samples was about the same as the reduction for matching to compound samples in both Experiments II and III (see Figure 2). It therefore appears that shared attention (element vs. compound samples) and competition among response alternatives (element vs. compound tests) seperately and noninteractively determine matching performance. In the present experiment, the added cues during comparison were made redundant. Therefore, the nontested elements appearing on the comparison keys were irrelevant following element samples, but were both redundant and relevant following compound samples. The results were consistent with the preceding argument that sample type and test type have independent effects on matching. Performance was still harmed in this experiment by the presence of irrelevant cues (element sample - compound test vs. element sample - element test) but the effect of test type was eliminated by the presence of redundant, relevant cues (compound sample - compound test vs. compound sample - element test). However, eliminating competing sources of control by using redundant, relevant cues in compound comparison stimuli did not attenuate the effects of compound samples, i.e., the shared attention decrement.

\section{GENERAL DISCUSSION}

There are a number of alternative hypotheses which can account for the decrement observed in matching simple stimuli to compound samples. The shared attention hypothesis localizes the decrement during sample presentation. That is, an inverse relationship of more or less linear form describes the stimulus control exerted by two elements of a compound sample. To the extent that both elements control matching, control by each will be attenuated relative to control by that element when presented alone. The generalization decrement hypothesis is a strong competitor. This explanation emphasizes physical differences between a compound sample and an only nominally matching elemental comparison stimulus. Hence, if anything, this hypothesis localizes the compound-matching decrement during presentation of comparison (test) stimuli.

In light of data obtained in Experiments II-IV, the explanatory power of the generalization decrement hypothesis is seriously weakened. The prediction from the hypothesis is that testing compound-sample control with an identical compound-comparison stimulus should reverse the difference between performances maintained by element and compound samples with element comparison stimuli. Therefore, perfectly disordinal interactions between sample type and test type should have resulted from Experiments II and IV. The plots in
Panels II and IV of Figure 2 should then be X-shaped. Clearly they are not, so the generalization decrement hypothesis was not supported.

The present dismissal of the generalization decrement hypothesis is consonant with Carter and Eckerman's (1975) conclusion that ease of learning MTS does not depend on similarity between sample and comparison stimuli. Their results showed that, when corrected for discriminability among sample and comparison stimuli, rates of learning MTS and symbolic matching were the same. They suggested that in acquiring MTS, pigeons learn sample-specific "if...then..." rules. This notion was recast in this paper in terms of MTS performance and called the rule hypothesis. Like the generalization decrement hypothesis, the rule hypothesis also predicted interactions (but of a different form) between sample type and test type in Experiments II and IV. In Panels II and IV of Figure 2 the lower, solid line (representing compound test trials at one rule/sample) should be completely flattened and displaced upwards to the highest point plotted on the dotted line (which represents element sample - element comparison trials, also at one rule/sample). Again, the obtained pattern of results conflicts with that predicted.

So far, this paper has selectively attended to the data presented in Figure 2 and the evaluation of competing explanations of the different performances maintained by element vs. compound samples. Another novel result of Experiments II-IV was that sample duration and test type interactively determined matching accuracy (Figure 1). One interpretation is that restricting stimulus duration weakens sample control so that additional cues present during comparison play a more prominent role in controlling choice behavior. Hence, the drop in performance due to the presence of these cues (element tests vs. compound tests) is largest for brief samples. Alternatively, it could be argued that sample duration and test type interact simply because of converging performances at the limiting extremes $(50 \%$ and $100 \%$ correct). Neither interpretation is incompatible with describing the results of these experiments in terms of shared attention (during sample presentation) and competing sources of stimulus control (during comparison).

The foregoing implies that compound samples and compound comparison stimuli are processed by the pigeons as their separate elements, not as unitary stimuli. This is a perfectly reasonable interpretation given the birds' long history of matching elemental stimuli to compound samples. Were it otherwise, i.e., if compounds were encoded as compounds rather than as separate elements, predictions generated by the generalization decrement hypothesis would be reasonably accurate with respect to the data presented in Figure 2.

Finally, a note is in order concerning sporadic observations of interactive control by matching by sample type and sample duration (Experiments II and III). A much too simplistic explanation of the compound-matching 
decrement conceptualizes control by a compound sample to by achieved by one element or the other element during any trial. If this were the case, compound-matching scores would lie halfway between element-matching scores (attention to the tested element) and chance (attention to the nontested element). In all of the experiments conducted to date (Experiments I-IV; Leith \& Maki, 1975; Maki \& Leith, 1973; Maki \& Leuin, 1972), this prediction has not been confirmed; compounds were consistently matched better than predicted. Now, it may be that attention is "switched" quickly between elements of a compound sample, or that processing of elements proceeds in parallel. Each of these models of processing complex stimuli might predict convergence of matching performances sustained by element and compound samples at long sample durations. The data accumulated thus far do not allow a distinction, and it is not clear if such a distinction is even possible (Lindsay, 1970).

\section{REFERENCE NOTES}

1. Farthing, G. W., \& Opuda, M. J. Selective attention in matching-to-sample in pigeons. Paper read at the Eastern Psychological Association meeting. Washington, 1973.

\section{REFERENCES}

Blough, D. S. Attention shifts in a maintained discrimination. Science, $1969,166,125-126$.

Born, D. G., \& Peterson, J. L. Stimulus control acquired by the components of two color-form compound stimuli. Journal of the Experimental Analysis of Behavior, 1969, 12, 437-442.

Carter, D. E., \& Eckerman, D. A. Symbolic matching by pigeons: Rate of learning complex discriminations predicted from simple discriminations. Science, $1975,187,662-664$.

Cumming, W. W., \& Berryman, R. The complex discriminated operant: Studies of matching-to-sample and related problems. In D. I. Mostofsky (Ed.), Stimulus generalization. Stanford: Stanford University Press, 1965. Pp. 284-330.

Johnson, D. R., \& Cumming, W. W. Some determiners of attention. Journal of the Experimental Analysis of Behavior, $1968,11,157-166$.

Kamin, L. J. Selective association and conditioning. In N. J. Mackintosh \& W. K. Honig (Eds.), Fundamental issues in associative learning. Halifax: Dalhousie University Press, 1969.

Leith, C. R., \& Maki, W. S., Jr. Attention shifts during matchingto-sample performance in pigeons. Animal Learning \& Behavior, $1975,3,85-89$.

Lindsay, P. H. Muitichannel processing in perception. In D. I. Mostofsky (Ed.), Attention: Contemporary theory and analysis. New York: Appleton-Century-Crofts, 1970.

Pp. 149-171.
Mackintosh, N. J. Selective attention in animal discrimination learning. Psychological Bulletin, 1965, 64, 124-150.

Maki, W. S., Jr., \& Leith, C. R. Shared attention in pigeons. Journal of the Experimental Analysis of Behavior, 1973, 19, 345-349.

Maki, W. S., Jr., \& Leuin, T. C. Information processing by pigeons. Science, $1972,176,535-536$.

Reynolds, G. S. Attention in the pigeon. Journal of the Experimental Analysis of Behavior, 1961, 4, 203-208.

Sutherland, N. S. \& Mackintosh, N. J. Mechanisms of animal discrimination learning. New York: Academic Press, 1971.

(Received for publication February 19, 1975. Revision accepted July 17, 1975.)

\section{NOTES}

1. Other effects were significant, but unstable across experiments; these are reported without comment. Sample type and sample set interacted; the superiority of element matching was greatest for line matching $[F(1 / 79)=5.22, p<.05]$. The difference between color and line matching depended on sample duration $[F(4 / 79)=7.32, p<.001]$; at the four shortest durations color matching was best performed, but at the longest duration line matching was best. Finally, the difference between color and line matching performances varied over sessions in an unsystematic but significant $[F(3 / 79)=4.12, p<.01]$ way, resulting in a significant $[F(3 / 79)=5.32, p<.01]$ but unsystematic effect of sessions.

2. Test type also interacted with sessions $[F(4 / 199)=4.71$, $\mathrm{p}<.011$. Performance during element tests improved over sessions, but performance during compound tests remained stable. The sessions main effect was also significant $[F(4 / 199)=$ $2.98, \mathrm{p}<.05]$

3. Both sample type and test type interacted with sample set. The effects of test type were larger, for colors $[F(1 / 199)=11.43$ $p<.011$, while the effects of sample type were larger for lines $[F(1 / 199)=4.17, p<.05]$. Line matching performance tended to converge on color matching performance at longer sample durations $[F(4 / 199)=4.91, p<.01]$. Performance during element tests improved more over sessions than did performance during compound tests $[F(4 / 199)=2.95, p<.05]$, resulting in a significant main effect of sessions $[F(4 / 199)=13.90$ p $<001]$. Matching to samples of intermediate durations improved most over sessions $[F(16 / 199)=2.06, p<.05]$. Finally, the Sample Type by Sample Duration interaction was largest during element tests $[F(4 / 199)=3.14, p<.05]$.

4. Also, performance slightly improved over sessions $[F(4 / 199)=6.88, p<.001]$. The effects of test type were larger for colors than for lines $[F(1 / 199)=22.43, p<.001]$, while the effects of sample type were larger for lines than for colors $[F(1 / 199)=4.13, p<.05]$. The latter interaction was not apparent in the data of Bird No, 69.

5. When compound samples were followed by compound comparison stimuli containing redundant, relevant cues, sample set was a "dummy" variable. That is, because matching could be based on either color or line orientation during these trials, identifying a particular trial with one sample set would be meaningless. However, the distinction was preserved for purposes of counterbalancing, data collection, and analysis, and is maintained in Table 5 . 